\title{
Differential Regulation of Calcium/Calmodulin-Dependent Protein Kinase II and p42 MAP Kinase Activity by Synaptic Transmission
}

\author{
Timothy H. Murphy, ${ }^{1}$ Lothar A. Blatter, ${ }^{3, a}$ Ratan V. Bhat, ${ }^{1,2}$ Rachel S. Fiore, ${ }^{1}$ W. Gil Wier, ${ }^{3}$ and Jay M. Baraban ${ }^{1,2}$ \\ Departments of ${ }^{1}$ Neuroscience and ${ }^{2}$ Psychiatry and Behavioral Sciences, Johns Hopkins University School of Medicine, \\ Baltimorc, Maryland 21205-2185, and ${ }^{3}$ Department of Physiology, University of Maryland School of Medicine, Baltimore, \\ Maryland 21201
}

Calcium/calmodulin-dependent protein kinase II (CaMK) and p42 mitogen-activated protein kinase (MAPK) are enriched in neurons and possess the capacity to become persistently active, or autonomous, following removal of the activating stimulus. Since persistent kinase activation may be a mechanism for information storage, we have used primary cultures of cortical neurons to investigate whether kinase autonomy can be triggered by bursts of spontaneous synaptic activity. We and others have found that both these kinases respond to synaptic stimulation, but differ markedly in their kinetics of activation and inactivation, as well as in their sensitivity to NMDA receptor blockade. While $90 \%$ of maximal CaMK activation was observed after only $10 \mathrm{sec}$ of synaptic bursting, MAPK activity was unaffected at this early time and rose to only $30 \%$ of maximal after 2 min of stimulation. Following blockade of synaptic stimulation, CaMK activity decreased by $50 \%$ in $10-30$ sec, while MAPK activity decayed by $50 \%$ within 6-10 min. Although MAPK exhibited relatively slow activation, short periods of synaptic activity could trigger the MAPK activation process, which persisted in the absence of synaptic stimulation.

Comparison of the effect of NMDA receptor blockade on synaptic activation of these kinases revealed that CaMK activity is preferentially suppressed. As previous immunocytochemical studies indicate that CaMK is concentrated in dendritic processes in the vicinity of synapses, we measured synaptic calcium transients in fine dendritic processes $(\sim 1$ $\mu \mathrm{m}$ diameter) to assess their sensitivity to NMDA receptor blockade. Calcium transients in these fine processes were reduced by up to $90 \%$ by NMDA receptor blockade, possibly accounting for the profound sensitivity of CaMK to this treatment. The sharp contrast between the regulation of CaMK and MAPK by synaptic activity indicates that they may mediate neuronal responses to different patterns of afferent stimulation. The relatively slow activation and inactivation

Received Mar. 23, 1993; revised Aug. 13, 1993; accepted Aug. 19, 1993.

This work was supported by an NRSA Fellowship (T.H.M.), U.S. Public Health Service Grant DA-00266, and RSDA Grant MH-00926 (J.M.B.). We thank Darla Rodgers for excellent secretarial assistance, Howard Schulman and Melanie $\mathrm{MacNicol}$ for advice on kinase assays and for providing monoclonal antibodies to CaMK, and J. Cooper for antibodies to MAPK

Correspondence should be addressed to Timothy H. Murphy, Ph.D., Iohns Hopkins University, Department of Neuroscience, 908 WBSB, 725 North Wolfe Street, Baltimore, MD 21205-2185.

a Present address: Department of Physiology, Loyola University of Chicago, Maywood, IL 60153.

Copyright (C) 1994 Society for Neuroscience $0270-6474 / 94 / 141320-12 \$ 05.00 / 0$ of MAPK suggests that it may be able to integrate information from multiple, infrequent bursts of synaptic activity.

IKey words: glutamate, long-term potentiation, phosphorylation, intracellular calcium, neuronal plasticity]

Synaptic activation of multiple protein kinases has been implicated in mediating neuronal plasticity (Bashir and Collinridge, 1992). However, relatively little is known about the synaptic mechanisms underlying activation of specific kinases, or the duration of kinase activity once induced. Both calcium $/$ calmodulin-dependent protein kinase II (CaMK) (Hanson and Schulman, 1992; Kelly, 1992) and p42 mitogen-activated protein kinase (MAPK) (Cobb et al., $1991 \mathrm{a}, \mathrm{b}$; Pelech and Sanghera 1992) are activated by neurotransmitter receptor stimulation (Stratton et al., 1989; MacNicol et al., 1990; Bading and Greenberg, 1991) and are located in neuronal cell bodies and dendrites (Kennedy et al., 1990; Fiore et al., 1993a). Furthermore, both are phosphorylated during activation, rendering them autonomous or persistently active in the absence of stimulation. To achieve this persistently active state, CaMK undergoes autophosphorylation upon binding calcium/calmodulin, which converts it to an active and $\mathrm{Ca}^{2+}$-independent form (Hanson and Schulman, 1992; Kelly, 1992). In contrast, MAPK is activated by phosphorylation of both tyrosine and threonine residues by an activator kinase (Ahn et al., 1992; Nakielny et al., 1992; Posada and Cooper, 1992; Rossomando et al., 1992). As this type of persistent kinase activity is thought to play a key role in neuronal plasticity (Lisman, 1985; Malinow et al., 1988; Klann et al., 1991), we wanted to ascertain how these kinases are regulated by synaptic activity, and whether their distinct mechanisms of activation would allow them to respond to different components of synaptic transmission. To address this question, we have used primary cultures of cortical neurons, as these are well suited for both physiological recordings of synaptic activity and biochemical assays of kinase activity.

\section{Materials and Methods}

Cortical cultures were made from 17-18-d-gestation rat fetuses as previously described (Murphy and Baraban, 1990), and kept in vitro for at least $21 \mathrm{~d}$ for all experiments performed. Electrophysiological recordings and fluo-3 $\mathrm{Ca}^{2}$ measurements (Minta et al., 1989) were performed as previously described at room temperature (Murphy et al., 1991a) using a Hanks' balanced salt solution (HBSS) that contained (in mM) 137 $\mathrm{NaCl}, 5.0 \mathrm{KCl}, 2.5 \mathrm{CaCl}_{2}, 1.0 \mathrm{MgSO}_{4}, 0.44 \mathrm{KH}_{2} \mathrm{PO}_{4}, 0.34$ $\mathrm{Na}_{2} \mathrm{HPO}_{4}\left(7 \mathrm{H}_{2} \mathrm{O}\right), 10 \mathrm{Na}^{+} \mathrm{HEPES}, 1 \mathrm{NaHCO}_{3}, 1 \mathrm{NaHCO}_{3}, 5$ glucose (pH 7.4 and $340 \mathrm{mOsm}$; in some cases $\mathrm{Ca}^{2+}$ and $\mathrm{Mg}^{2+}$ levels were modified as indicated). In previous experiments using fura-2, we found that $\mathrm{Ca}^{2+}$ transients recorded over the cell soma of cortical neurons 
during synaptic bursting ranged from a resting level of $50 \mathrm{nM}$ to 600 nM peaks (Murphy et al., 1992b). These changes in $\left[\mathrm{Ca}^{2+}\right]$ would be expected to be within the linear range of the fluo-3 response (Minta et al., 1989).

CaMK immunoprecipitation and cyanogen bromide ( $C N B r)$ cleavage. Cortical cultures plated in $35 \mathrm{~mm}$ dishes were washed once with phosphate-free HBSS and incubated at $37^{\circ} \mathrm{C}$ for $3-4 \mathrm{hr}$ with $1 \mathrm{mCi} / \mathrm{ml}(1$ $\mathrm{ml}$ volume) of ${ }^{32} \mathrm{P}$ orthophosphate (in phosphate-free HBSS). The labeling medium was then removed and replaced with HBSS (phosphatefree) containing inhibitors or activators of synaptic transmission for an additional 15-20 min. After stimulation, the medium was rapidly removed and cold stop buffer containing $10 \mathrm{~mm} \mathrm{Na}{ }^{+}$phosphate $\mathrm{pH} 7.2$, $150 \mathrm{~mm} \mathrm{NaCl}, 1 \mathrm{~mm}$ EGTA, $50 \mathrm{~mm} \mathrm{NaF}, 1 \mathrm{~mm}$ phenylmethylsulfonyl fluoride, $1 \%$ Nonidet $\mathrm{P}-40,1 \% \mathrm{Na}^{+}$deoxycholate, $0.1 \% \mathrm{SDS}$, and $1 \mu \mathrm{M}$ okadaic acid was added. The dishes were then scraped on ice, and the cell lysate transferred to microcentrifuge tubes and spun at $15,000 \times g$ for $25 \mathrm{~min}$. The supernatants were then removed and monoclonal antibodies to the $\alpha$ - and $\beta$-subunits of CaMK (1:2500 dilution of sera CB$\beta 1$, and CB- $\alpha 2$ ) (MacNicol et al., 1990) were added at the same time as protein A Sepharose (Pharmacia). After $1.5 \mathrm{hr}$ of incubation at $4^{\circ} \mathrm{C}$, the protein A Sepharose was pelleted and washed at least five times in homogenization buffer. The pellet was then analyzed by SDS-PAGE (Laemmli, 1970). Two major bands corresponding to the $\alpha$ - and $\beta$-subunits of $\mathrm{CaMK}$ were observed in autoradiograms of the dried gels. These bands were then excised and radioactivity quantified by Cerenkov counting. To pcrform $\mathrm{CNBr}$ clcavage, the gel slices were swelled and crushed in a solution containing $50 \mathrm{~mm}$ tetraethylammonium, $0.5 \mathrm{~mm}$ EDTA, 1\% SDS (Schworer et al., 1988; Fukunaga et al., 1989). Proteins were eluted during a $24 \mathrm{hr}$ incubation at $4^{\circ} \mathrm{C}$ under gentle agitation (recovery was typically greater than $70 \%$ ). Soluble material was collected and trichloroacetic acid (TCA) precipitated ( $10 \%$ final TCA concentration) in the presence of $20 \mu \mathrm{g}$ of cytochrome $\mathrm{C}$ carrier protein. The resulting pellet was then washed with acetone and incubated overnight in $100 \mu \mathrm{l}$ of $70 \%$ formic acid and $25 \mathrm{mg} / \mathrm{ml} \mathrm{CNBr}$, at room temperature. The material was then lyophilized, washed twice with $\mathrm{H}_{2} \mathrm{O}$, and resuspended in gel sample buffer. An aliquot was counted and the volumes of the samples were corrected for recovery (based on radioactivity present in original SDS-PAGE gel slices). Labeled peptides were then resolved using a $15 \%$ acrylamide SDS urea gel, which was then dried and autoradiography performcd.

Phosphotyrosine and MAPK Western blots. Extracts of soluble proteins [ $40 \mu \mathrm{g}$ determined by the bicinchoninic acid (BCA) method] from cortical cultures were resolved by SDS/PAGE and transferred to nitrocellulose membranes electrophoretically. The membranes were then probed with monoclonal antibodies to phosphotyrosine (4G10, UBI). Blots were then reprobed with an antiserum raised against a peptide corresponding to the C-terminus of rat p44 MAPK (CGGPFTFDMELDDLPKERLKELIFQETARFQPGAPEAP; obtained from UBI), which cross-reacts with p42 MAPK (Baraban et al., 1993), or a monoclonal antibody specific for p42 MAPK (UBI).

Kinase assays. Cortical cultures were treated with agonists or agents that modify synaptic transmission as described in Results and figures. After the indicated period of stimulation, the medium was rapidly removed and to the culture dishes was added cold stop buffcr $(0.4 \mathrm{ml} / 35$ $\mathrm{mm}$ plate) containing Tris, $20 \mathrm{~mm}$ pH 7.5; okadaic acid, $1 \mu \mathrm{M}$; EGTA, $0.5 \mathrm{~mm}$; EDTA, $1 \mathrm{~mm}$; leupeptin, $10 \mu \mathrm{g} / \mathrm{ml}$; pyrophosphate, $10 \mathrm{~mm}$; molybdate, $0.4 \mathrm{~mm}$; dithiothreitol (DTT), $2 \mathrm{~mm}$; Na+ vanadate, $1 \mathrm{~mm}$; and para-nitrophenylphosphate, $500 \mu \mathrm{m}$. The cells were scraped in this solution and then sonicated on ice for about $2 \mathrm{sec}$ using a probe sonicator.

$\mathrm{Ca}^{2+} /$ calmodulin-dependent and -independent CaMK activity was measured as described by Ocorr and Schulman (1991) using a synthetic substrate AC-2 (KKALRRQETVDAL; $20 \mu \mathrm{M}$ ) that resembles the CaMK autophosphorylation site. Although significant changes in $\mathrm{Ca}^{2+} / \mathrm{cal}-$ modulin-independent activity were observed, none of the treatments used significantly affected $\mathrm{Ca}^{2+}$-dependent CaMK activity, or kinase activity measured in the absence of peptide (blank). Both $\mathrm{Ca}^{2+}$-dependent and -independent kinase activities (from stimulated and unstimulated cultures) were reduced by a peptide corresponding to the autoinhibitory domain of CaMK (273-302) (Malinow et al., 1989), with $\mathrm{IC}_{50}$ values of less than $15 \mu \mathrm{M}$, while another peptide lacking arginine 283 that is critical for autoinhibition (CaMK 284-302) lacked any significant inhibition at 15-30 $\mu \mathrm{M}$. Peptide inhibitors specific for cAMPdependent protein kinase (PKI-tide) and protein kinase C (pseudosubstrate; PKC 19-36) had no effect on $\mathrm{Ca}^{2+}$-independent or $\mathrm{Ca}^{2+}$-stim- ulated CaMK activity, when included in the assay buffer at $20 \mu \mathrm{M}$. Results are expressed as the percentage of autonomous CaMK, which was calculated as $\left(\mathrm{Ca}^{2+} /\right.$ calmodulin-independent activity - blank $) /\left(\mathrm{Ca}^{2+} /\right.$ calmodulin-dependent activity - blank) $\times 100$. The velocity of CaMK ( $P_{i}$ incorporated $/ \mathrm{min} \mathrm{mg}$ protein) was calculated by dividing $\mathrm{CaMK}$ activity by the total protein concentration in the cell extract determined by the BCA method (Pierce). Inclusion of NMDA receptor antagonists [D,L-aminophosphonovalerate (D,L-APV), $200 \mu \mathrm{M} ; \mathrm{MK}-801,3 \mu \mathrm{M}$ ] in the CaMK assay buffer had no significant effect on $\mathrm{Ca}^{2+}$-independent or $\mathrm{Ca}^{2+}$-dependent $\mathrm{CaMK}$ activity. Furthermore, no significant reduction in CaMK autonomy was observed if $\mathrm{D}, \mathrm{L}-\mathrm{APV}(200 \mu \mathrm{M})$ was added during cell lysis, which suggested that NMDA receptors were not being activated by the cell lysis procedure.

MAPK activity was measured using a synthetic peptide corresponding to the MAPK phosphorylation site of myelin basic protein (MBP) (APRTPGGRR) (Erickson et al., 1990; Clark-Lewis et al., 1991). This peptide $(1.3 \mathrm{~mm})$ was dissolved in a buffer containing $13 \mathrm{~mm} \mathrm{MgCl}$, $1.3 \mathrm{~mm}$ DTT, $66 \mu \mathrm{M}{ }^{32} \mathrm{P}$-ATP $(30-60 \mu \mathrm{Ci} / \mathrm{ml}) 36 \mathrm{~mm}$ Tris pH 7.4, 33 $\mathrm{mM} \mathrm{NaCl}$, and $1.3 \mathrm{~mm} p$-nitrophenylphosphate. Phosphorylation of the MBP peptide reflects MAPK activity since fractionation of soluble extracts from synaptically active cortical cultures on a MonoQ column yields a single peak of MBP phosphorylation activity and this peak coelutes with MAPK immunoreactivity. Thus, under the conditions used, other protein kinases would not be able to phosphorylate the MBP substrate appreciably (Fiore et al., 1993b). As expected, MAPK activity appeared to be dependent on tyrosine phosphorylation since omission of tyrosine phosphatase inhibitors from the cell lysis buffer resulted in a greater than $75 \%$ loss in activity toward the MBP peptide substrate. Inclusion of peptide inhibitors specific for PKI-tide $(20 \mu \mathrm{M})$ and PKC (pseudosubstrate; PKC 19-36; $20 \mu \mathrm{M}$ ) in the MAPK assay buffer had no effect on basal or stimulated phosphorylation of the MBP substrate in extracts derived from cortical cultures.

To perform the MAPK assay, soluble cell extract $(240,000 \times g$ supernatant) in the homogenization buffer described above $(10 \mu \mathrm{l})$ was added to $30 \mu \mathrm{l}$ of peptide- and ATP-containing buffer, mixed, and incubated at $30^{\circ} \mathrm{C}$ for $10 \mathrm{~min}$ (within the linear range of activity) before stopping the reaction by addition of $10 \mu \mathrm{l}$ of $100 \%$ TCA wt/vol. TCAsoluble material (separated by centrifugation) was then spotted onto Whatman P81 phosphocellulose papers and washed for $1 \mathrm{hr}$ in $0.4 \%$ phosphoric acid. Incorporated radioactivity was determined using liquid scintillation counting. In experiments comparing MAPK and CaMK activation by synaptic stimulation, MAPK activity was normalized to the amount of $\mathrm{Ca}^{2}$-stimulated CaMK activity (which did not change with any of the treatment conditions). Similar results were obtained by normalizing MAPK activity to protein concentration measured by the BCA assay.

Dendritic $\mathrm{Ca}^{2+}$ imaging with fura-2. Cortical neurons were impaled with 40-60 M $\Omega$ microelectrodes that were filled (tip only) with $10 \mathrm{~mm}$ fura-2 (K+ salt, Molecular Probes) in $200 \mathrm{~mm} \mathrm{KCl}$. The remainder of the electrode was back-filled with $2 \mathrm{M} \mathrm{KCl}$. Dye injection was facilitated by current injection $(\sim 2 \mathrm{nA})$ and pressure application $(3 \mathrm{ml}$ compression of a $30 \mathrm{ml}$ syringe) over a $5-10 \mathrm{~min}$ period. Electrodes were then removed, and the cells were allowed to recover in HBSS containing TTX for about $2 \mathrm{hr}$ before assessing intracellular $\mathrm{Ca}^{2+}$ transients. Of the neurons impaled, only those (about 10-20\%) that showed low resting $\mathrm{Ca} 2+$ and spontaneous activity were considered suitable for study. $\mathrm{Ra}-$ tiometric fura-2 imaging was then performed as described (Blatter and Wier, 1992). The fura- 2 signal was calibrated in vitro using a fura-2 salt solution containing no added calcium (EGTA buffered) or a saturating concentration of calcium.

\section{Results}

\section{Synaptic activation of $C a M K$ and $M A P K$}

In initial experiments, we investigated whether these kinases were regulated by spontaneous synaptic activity present in mature cortical cultures (Dichter, 1978; Murphy et al., 199la,b). In extracts prepared from synaptically active cultures, we observed basal autonomous activity for both kinases in assays using selective peptide substrates (Fig. 1 $A, B$ ). To test whether a component of either of these basal kinase activities was driven by spontaneous synaptic activity, we treated cultures for 20-30 min with $1 \mu \mathrm{M}$ TTX, which blocks action potential-dependent 

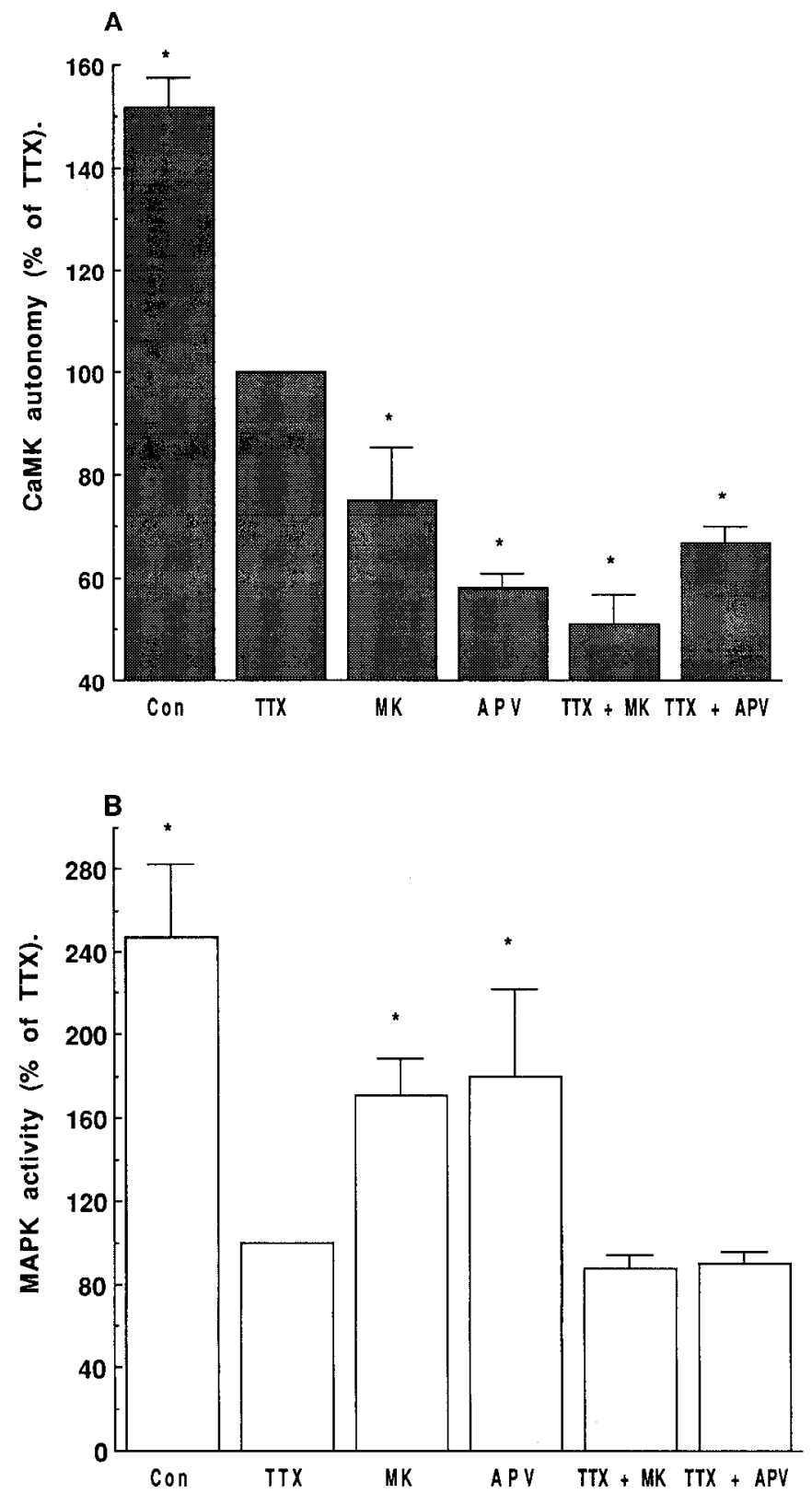

C

Fluo-3 Ca++ induced fluorescence (cell body).

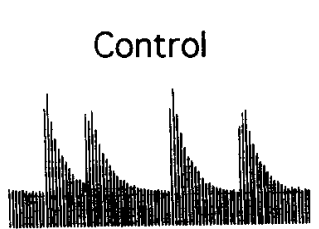

MK-801

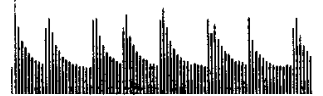

$2 \Delta F / F$

$20 \mathrm{sec}$ synaptic activity in these cultures (Murphy et al., 1991a,b), and observed that the stimulus-independent (autonomous) activities of both kinases were significantly depressed (Fig. $1 A, B$ ).

Since NMDA receptors mediate a component of the spontaneous synaptic currents and $\mathrm{Ca}^{2+}$ transients present in these cultured neurons (Murphy et al., 1991b, 1992b; Fig. 1C), we examined the role of these receptors in mediating kinase activation by assessing the effect of the selective NMDA receptor antagonists MK-801 or D,L-APV (Wong et al., 1986). Addition of either NMDA antagonist to cultures for 20-30 min reduced CaMK activity below levels seen following TTX treatment (Fig. $1 A$ ). The ability of NMDA antagonists to reduce CaMK activation even more effectively than TTX was unexpected, since synaptically mediated $\mathrm{Ca}^{2+}$ transients recorded over neuronal cell bodies were still present despite addition of NMDA receptor antagonists (Fig. 1C; Murphy et al., 1991a, 1992b). In contrast, NMDA antagonists were less effective than TTX in blocking MAPK activity, suggesting that synaptic activity mediated by NMDA receptors may preferentially activate CaMK. Additional evidence for differential regulation of MAPK and CaMK was obtained by examining the effect of NMDA receptor antagonists in the presence of TTX. In contrast to CaMK, no further reduction in MAPK activity was observed under these conditions.

Since NMDA receptor antagonists decreased CaMK activity below the level found in the presence of TTX, we hypothesized

Figure 1. Activity-dependent regulation of CaMK and MAPK. CaMK and MAPK activities were measured in synaptically active control cultures (10 $\mu \mathrm{M}$ picrotoxin, added for $10-20 \mathrm{~min}$ ) and picrotoxin-treated cultures pretreated with TTX $(1 \mu \mathrm{M}), \mathrm{MK}-801(3 \mu \mathrm{M})$, and/or D,L-APV $(200 \mu \mathrm{M})$ as indicated, for $20-30 \mathrm{~min}$ prior to addition of stop buffer. In control picrotoxin-treated cultures, activity typically consisted of 1 $5 \mathrm{scc}$ bursts of spikes and synaptic potentials that occurred rhythmically every 6-20 sec (Fig. 4A, bottom record; Murphy et al., 1992b). A, $\mathrm{Ca}^{2+}$. dependent and -independent CAMK activities were measured using a peptide substrate that resembles the autophosphorylation site of CaMK II. Autonomous activity was calculated as the ratio of $\mathrm{Ca}^{2+}$-independent to $\mathrm{Ca}^{2+}$-dependent kinase activity and then expressed as a percentage (\% autonomous CaMK). In TTX-treated cultures autonomous CaMK activity averaged $9.2 \pm 0.8 \%(n=17$ separate duplicate experiments). $\mathrm{Ca}^{2+}$-dependent activity averaged $5500 \mathrm{pmol}$ of $\mathrm{P}_{\mathrm{i}}$ incorporated $/ \mathrm{min}$ $\mathrm{mg}$ total protein and was not significantly altered by any of the treatments. To aid in the comparison of CaMK autonomous activity from different experiments, autonomous activity was expressed as a percentage of the activity found in TTX-treated cultures (TTX-treated = $100 \%$ ). $*, P<0.05$, one-way ANOVA comparing TTX-treated cultures to all other conditions (Fisher test used to assess significance). $B$, MAPK activity was measured using a synthetic substrate peptide based on the sequence surrounding the site in MBP phosphorylated by MAPK in vitro and expressed as a percentage of activity measured in TTX-treated cultures, $100 \%=63 \mathrm{pmol}$ of $\mathrm{P}_{\mathrm{i}}$ incorporated $/ \mathrm{min} \mathrm{mg}$ total soluble protein. Results are the means \pm SEM of at least three separate duplicate treatments assayed for each kinase. MAPK activity was normalized to the amount of calcium-stimulated CaMK activity, which did not vary with any of the treatment conditions. ${ }^{*}, P<0.05$, one-way ANOVA, comparing TTX-treated cultures to all other conditions as described above. $C$, Fluo- $3 \mathrm{Ca}^{2+}$-induced fluorescence recorded over the cell soma of a cultured cortical neuron in the presence of picrotoxin $(10 \mu \mathrm{M})$, and the same cell after the addition of the NMDA antagonist MK-801 (3 $\mu \mathrm{M}, 30 \mathrm{~min}$ ). Although this treatment only blocked somatic $\mathrm{Ca}^{2+}$ transients by $\sim 50 \%$, it was more effective than TTX alone at blocking CaMK activation. In the right panels, a different culture was treated with picrotoxin and TTX (20 min; note the complete absence of rhythmic aclivity). Under these conditions, blockade of NMDA receptors with 3 $\mu \mathrm{M}$ MK-801 (applied continuously for $20 \mathrm{~min}$ ) reduces CaMK autonomous activity. Although this treatment could affect CaMK autonomous activity, it has no effect on resting $\mathrm{Ca}^{2+}$ levels (as indicated by fluo-3 $\mathrm{Ca}^{2+}$-induced fluorescence) in the cell soma. 
A

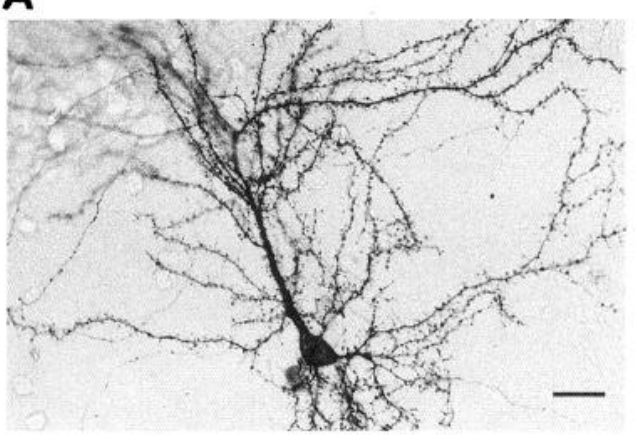

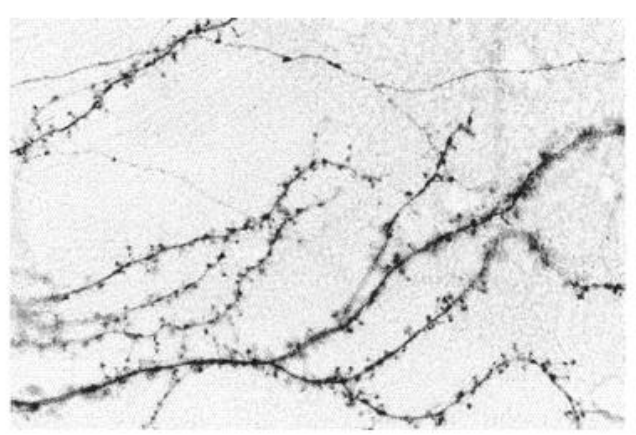
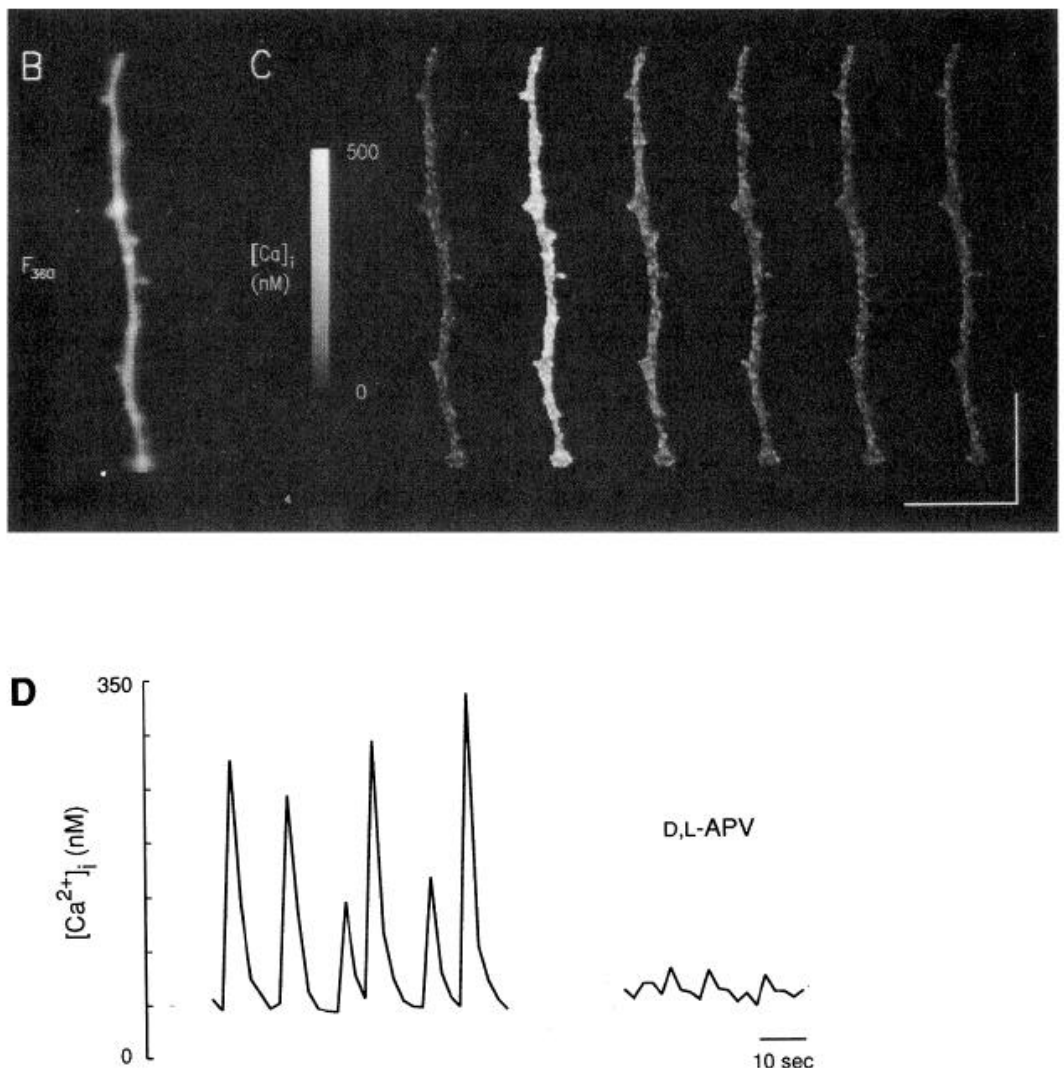

D,L-APV
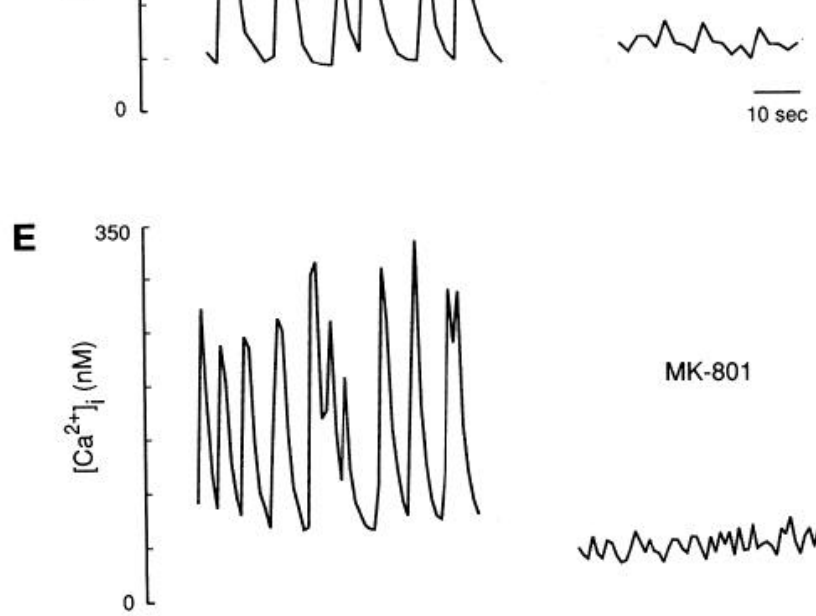

MK-801

MK-801 + TTX

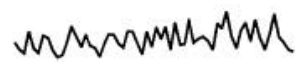

marumbuln

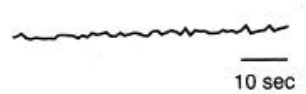

Figure 2. $\mathrm{Ca}^{2+}$ transients in fine dendritic processes are NMDA receptor dependent. $A$, Morphology of a single cultured cortical neuron perfused with $1 \%$ biocytin during whole-cell recording. This cell was subsequently fixed and processed using peroxidase reagents. The right panel is a high-power view of the upper right corner of this neuron. $B$, Raw $360 \mathrm{~nm}$ fluorescence image of a fine dendritic process similar to the region shown in the $A$, right. Cortical neurons were microinjected with the $\mathrm{K}^{+}$ salt of fura- 2 as described in Materials and Methods, and ratiometric $\mathrm{Ca}^{2+} \mathrm{im}-$ aging was performed during spontaneous synaptic activity in the presence of $10 \mu \mathrm{M}$ picrotoxin. $C$, Consecutive ratiometric calcium images taken every 2 $\mathrm{sec}$ of the dendritic process during spontaneous activity. $D$, Effect of the NMDA receptor antagonist D,L-APV on the amplitude of the spontaneous $\mathrm{Ca}^{2+}$ transients measured in the dendrite shown in $B$. Trace at left was taken prior to addition of $\mathrm{D}, \mathrm{L}-\mathrm{APV}$; trace at right is from same dendritic process following exposure to D,L-APV $(200 \mu \mathrm{M}$; $2 \mathrm{~min}$ ). Values shown in these tracings reflect the average calcium concentration over the entire dendritic segment shown in $B$. $E$, Noncompetitive NMDA receptor antagonist produces a similar reduction in dendritic calcium transients. The records shown are from a segment of a fine spiny dendrite similar to the one shown in $B$, which was pretreated for $10 \mathrm{~min}$ with $10 \mu \mathrm{M}$ picrotoxin. After $30 \mathrm{~min}$ of treatment with $3 \mu \mathrm{M}$ MK-801, dendritic $\mathrm{Ca}^{2+}$ transients were reduced by greater than $85 \%$. In the presence of MK-801 a small sig nal remains in dendrites, presumably due to action potential dependent synaptic stimulation, as it is completely suppressed by exposure to $1 \mu \mathrm{M}$ TTX for 5 min (both MK-801 + TTX were present). Scale bars: $A 25 \mu \mathrm{m}$ (left), 10 $\mu \mathrm{m}$ (right); $B$ and $C, 10 \mu \mathrm{m}$. 

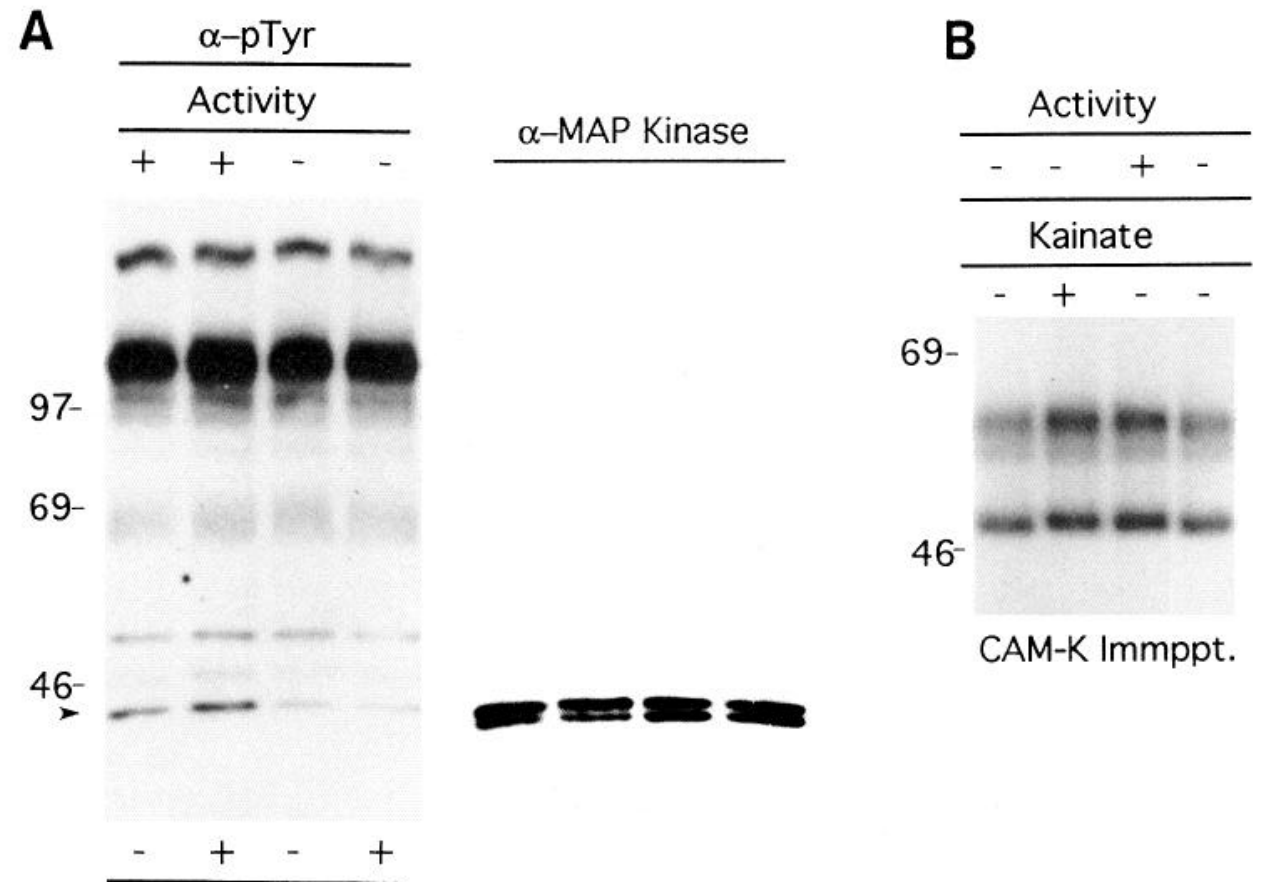

Fluo-3
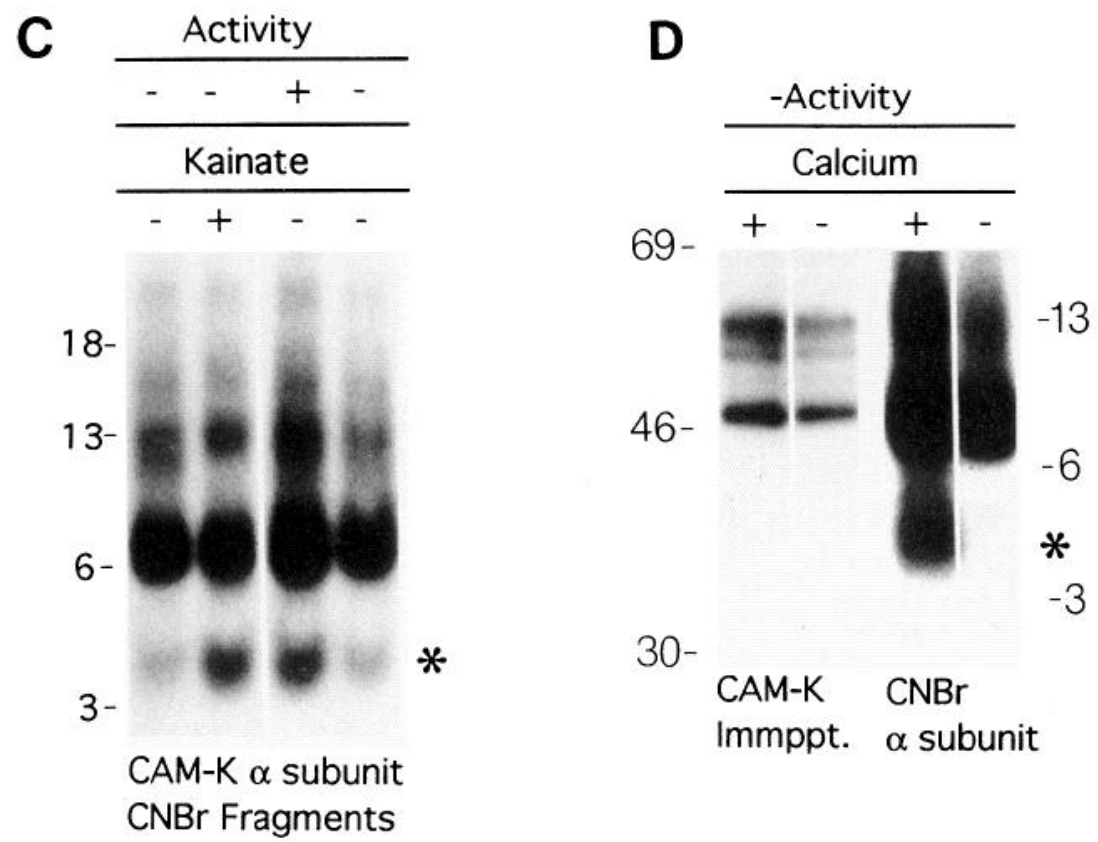

Figure 3. Activity-dependent phosphorylation of MAPK and CAMK. A, Phosphotyrosine immunoblot of soluble protein from synaptically active and inactive cultures. in the left lanes, + refers to cultures that were treated with picrotoxin $(10 \mu \mathrm{M})$ for 30 min and - refers to picrotoxin-treated cultures to which TTX $(1 \mu \mathrm{M})$ and the glutamate antagonist kynurenic acid $(1 \mathrm{mM})$ were added 10 min prior to the addition of stop buffer. Kynurenic acid was included to block the effect of glutamate released by action potential-independent mechanisms and to ensure that synaptic stimulation was rapidly blocked. Treatments were performed at room temperature. p42 MAPK comigrates with the phosphotyrosine-containing bands marked by the arrowhead. Comigration is indicated by stripping the phosphotyrosine blot and reprobing it with a monoclonal antibody to p42 MAPK $($ right $)$. On this blot MAPK migrates as a doublet consistent with the presence of a phosphorylated form. In some experiments, cultures were loaded with the $\mathrm{Ca}^{2+}$ indicator fluo-3 to monitor intracellular $\mathrm{Ca}^{2+}$ transients prior to preparation of extracts (as indicated). The Ca ${ }^{2+}$ indicator did not alter the phosphotyrosine status of MAPK. Molecular weights of standards in kilodaltons are indicated on the left for all films shown. $B$, Immunoprecipitation of CaMK $\alpha$ - and $\beta$-subunits from cultures metabolically labeled with ${ }^{32} \mathrm{P}_{\mathrm{i}}(1 \mathrm{mCi} / \mathrm{ml})$. After labeling, cultures were washed once before addition of medium containing picrotoxin (10 $\mu \mathrm{M}$, lane 3), or picrotoxin and inhibitors of electrical activity (TTX, $1 \mu \mathrm{M}$; MK-801, $3 \mu \mathrm{M}$; lanes 1,2,4) for an additional $20 \mathrm{~min}$ at room temperature. Kainate was added (as indicated, lane 2) 1 min before removal of medium and the addition of stop buffer. CaMK was then immunoprecipitated using antibodies to $\alpha$ - and $\beta$-subunits as described in Materials and Methods and resolved on SDS/PAGE. Autoradiogram shown is from a $15 \mathrm{~min}$ exposure of the dried gel. + refers to lanes with material from synaptically active cultures (lane 3); - refers to lanes with material from synaptically inactive cultures (treated with TTX and MK-801). Treatment of lane 2 with 
Table 1. Agonist stimulation of CaMK activity

\begin{tabular}{lc} 
Treatment & $\begin{array}{c}\text { CaM-kinase } \% \\
\text { autonomous } \\
\text { activity }\end{array}$ \\
\hline TTX & $8.5 \pm 1.3$ \\
TTX + NMDA, $10 \mu \mathrm{M}$ & $22.6 \pm 2.2^{*}$ \\
TTX + MK-801 & $5.2 \pm 1.0^{* *}$ \\
TTX + MK-801 + kainate, $30 \mu \mathrm{M}$ & $20.7 \pm 3.2^{*}$ \\
$-\mathrm{Ca}^{2+}, \mathrm{MK}-801+\mathrm{TTX}$ & $0.1 \pm 0.1$ \\
$-\mathrm{Ca}^{2+}, \mathrm{MK}-801+\mathrm{TTX}+$ kainate, $30 \mu \mathrm{M}$ & $4.1 \pm 1.4^{*}$ \\
\hline
\end{tabular}

Cultures were pretreated for $30 \mathrm{~min}$ at $37^{\circ} \mathrm{C}$ with blockers of synaptic activity (TTX, $1 \mu \mathrm{M}$, and MK-801, $3 \mu \mathrm{M}$, as indicated) before adding agonists for an additional $2 \mathrm{~min}$ prior to the addition of stop buffer. $-\mathrm{Ca}^{2+}$ indicates that treatments were performed in medium prepared without added $\mathrm{Ca}^{2+}$. CaMK activity is expressed as the ratio of $\mathrm{Ca}^{2+}$-independent to $\mathrm{Ca}^{2+}$-dependent phosphorylation of a CaMK peptide substrate. Values shown are the means \pm SEM of at least three separate duplicate experiments for each condition

${ }^{*} P<0.05$, paired $t$ test comparing each treatment to its respective control.

${ }^{* *} P<0.05$, paired $t$ test comparing CaMK activity in TTX treated cultures to cultures treated with TTX + MK-801.

that spontaneous (action potential-independent) release of glutamate may be sufficient to induce activation of CaMK. Consistent with this proposal, spontaneous miniature excitatory synaptic currents (MESCs) occurring at a frequency of $2.7 \pm 0.8$ $\mathrm{Hz}$ ( $n=7$ cells) were observed under whole-cell voltage clamp in the presence of TTX, picrotoxin, and normal extracellular $\mathrm{Mg}^{2+}$. The amplitude of these currents was reduced to background levels ( $n=10$ cells) by the broad spectrum glutamate antagonist kynurenic acid (1 mM; Monaghan et al., 1989), suggesting that they resulted from released glutamate. Thus, the presence of robust MESCs might account for CaMK activity that is insensitive to TTX, but blocked by NMDA receptor antagonists. An alternative explanation would be that the medium contains sufficient glutamate to activate NMDA receptors (Sah et al., 1989; Blanton et al., 1990). To investigate this further, we used an HPLC analysis, which failed to detect glutamate levels in excess of $0.2 \mu \mathrm{M}$ (data not shown) in the medium exposed to the cultures. Although the culture medium contains a very low glutamate concentration, local application of a glutamate antagonist (kynurenate, $2 \mathrm{~mm}$; in the absence of extracellular $\mathrm{Mg}^{2+},-100 \mathrm{mV}$ holding potential, to facilitate NMDA receptor activity) could produce sustained outward currents of $\sim 5 \mathrm{pA}$, indicating that tonic NMDA receptor activation may occur.

Since CaMK has been reported to be concentrated in dendritic processes in the vicinity of excitatory synapses (Kennedy et al., 1983,1990 ), we examined whether its profound sensitivity to NMDA receptor antagonists may reflect a predominant rolc of
NMDA receptors in mediating $\mathrm{Ca}^{2+}$ fluxes in distal dendrites and their associated spines (Fig. 2A). To examine $\mathrm{Ca}^{2+}$ transients in individual dendrites, we microinjected cortical ncurons with the $\mathrm{K}^{+}$salt of the $\mathrm{Ca}^{2+}$-sensitive probe fura-2 (Grynkiewicz et al., 1985). Regions corresponding to spiny distal dendrites (of less than $1 \mu \mathrm{m}$ in diameter and several hundred micrometers from the cell body) were identified and imaged during synaptic activity. Ratiometric imaging indicated a relatively homogeneous distribution of resting $\mathrm{Ca}^{2+}$ during the interval between spontaneous bursts. During spontaneous or electrically evoked bursts, intracellular $\mathrm{Ca}^{2+}$ increased over the entire dendrite and associated spines. The increase in $\mathrm{Ca}^{2+}$ was reduced by greater than $90 \%$ by the NMDA receptor antagonist $\mathrm{D}, \mathrm{L}-\mathrm{APV}(200 \mu \mathrm{M})$ in five of five cells. The effect of D,L-APV was reversed by washing. Similar results were also obtained following treatment with $3 \mu \mathrm{M}$ MK-801, which was able to decrease the amplitude of the dendritic $\mathrm{Ca}^{2+}$ transients by $85 \%$. Since these neurons have extensive dendritic arbors that account for most of their volume (Fig. 24), the ability of NMDA receptor antagonists to attenuate calcium transients greatly in this compartment may help explain the marked suppression of CaMK activity observed in homogenates.

As neuronal preparations appear to differ considerably in their levels of basal and agonist-stimulated CaMK activities (Molloy and Kennedy, 1991; Fukunaga et al., 1992), we compared the response of $\mathrm{CaMK}$ to synaptic stimulation with that clicited by glutamate receptor agonists. Addition of NMDA $(10 \mu \mathrm{M})$ to synaptically inactive cultures (TTX treated) increased CaMK autonomous activity from $9 \%$ to $22 \%$. Since synaptically activated CaMK was particularly sensitive to NMDA receptor antagonists, we assessed whether this blockade could be overcome by stimulation of other glutamate receptor classes. Activation of non-NMDA glutamate receptors with $30 \mu \mathrm{M}$ kainate produced a similar rise in CaMK autonomy. Kainate's effect was $\mathrm{Ca}^{2+}$ dependent since only small increases in CaMK autonomy were observed in the absence of added extracellular $\mathrm{Ca}^{2+}$ (Table 1).

\section{Phosphorylation of CaMK and MAPK}

Results of the peptide kinase assays described above suggested that synaptic activity elicits autonomous MAPK and CaMK activities. As an independent check on these assays of kinase activity, we also determined whether synaptic transmission leads to phosphorylation of the expected regulatory sites. Autonomous CaMK activity is generated after autophosphorylation of Thr 286 ( $\alpha$-subunit) (Hanson and Schulman, 1992), while MAPK activity requires phosphorylation on both Thr and Tyr residues (Anderson et al., 1990; Payne et al., 1991). To monitor changes in tyrosine phosphorylation of MAPK, immunoblots of cortical

\section{$\leftarrow$}

kainate is indicated by + . The kainate treatment shows that the effect of the inhibitors used to block synaptic activity can be overcome by direct stimulation. $C, \mathrm{CNBr}$ cleavage of the CaMK $\alpha$-subunits. Labeled bands corresponding to the $\alpha$-subunit of CaMK (material from $B$ ) were excised from the dried gel, eluted overnight, and $\mathrm{CNBr}$ cleaved. The $\mathrm{CNBr}$ cleaved material was then run on a high-percentage urea gel and exposed to film for about $2 \mathrm{hr}$ to produce the autoradiogram shown. The band denoted by the asterisk corresponded to the position of a CNBr fragment shown previously by Schworer et al. (1988) to contain the autophosphorylation site of CaMK. The radioactivity associated with this band increased by $230 \%$ with kainate depolarization and $180 \%$ in synaptically active cultures, while the $6 \mathrm{kDa}$ band increased by less than $40 \%$ with either stimulus (determined by liquid scintillation counting of the excised bands). $D$, Effects of low extracellular $\mathrm{Ca}^{2+}$ on CaMK phosphorylation in synaptically inactive cultures. Cultures were labeled as described in Figure $2 B$ and treated with TTX and MK-801 (which block synaptic activity) in the presence or absence of added extracellular $\mathrm{Ca}^{2+}(2.5 \mathrm{~mm})$ for $20 \mathrm{~min}$ at room temperature before adding stop buffer. Left two lanes are of immunoprecipitated $\alpha$ - and $\beta$-subunits as described for $B$. Right two lanes are the CNBr cleavage products of the $\alpha$-subunit for each condition (as in $C$ ). $\mathrm{CNBr}$ cleavage of the $\alpha$-subunit of CaMK indicates that the residual CaMK regulatory autophosphorylation that persists in the presence of TTX and MK-801 is dependent on extracellular $\mathrm{Ca}^{2+}$ (site indicated by an asterisk). The autoradiogram shown was intentionally overexposed (relative to the exposure for similar conditions in $C$ ) to emphasize that in the absence of added extracellular calcium no detectable phosphorylation of this site was present. 
A

\section{$0.5 \mathrm{mM} \mathrm{CaCl} 2$}

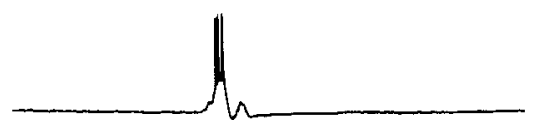

$2.25 \mathrm{mM} \mathrm{CaCl} 2$

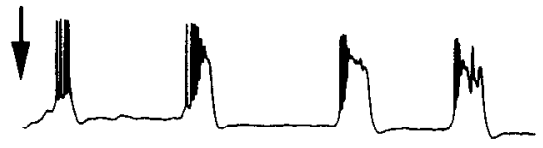

$30 \min 2.25 \mathrm{mM} \mathrm{CaCl} 2$

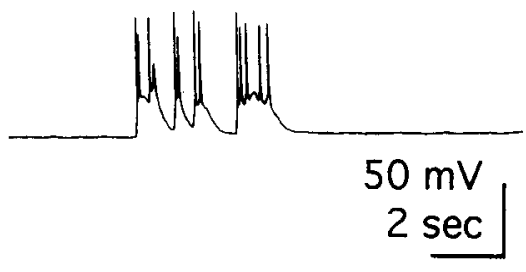

B

\section{Fluo-3 $\mathrm{Ca}++$ induced fluorescence}
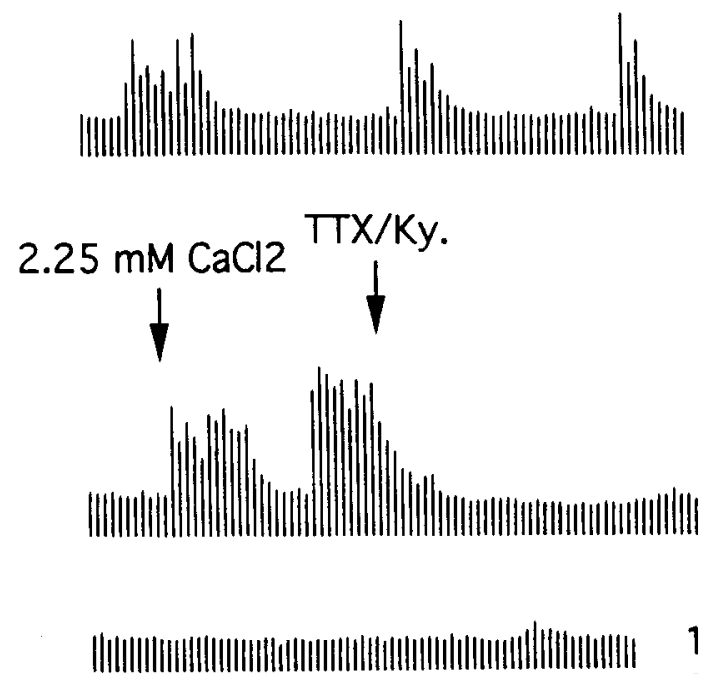

$1 \Delta \mathrm{F} / \mathrm{F}$ $10 \mathrm{sec}$

Figure 4. Rapid modulation of spontaneous activity. $A$, Effect of reduced extracellular $\mathrm{Ca}^{2+}$ and increased $\mathrm{Mg}^{2+}$ on spontaneous firing. Cells were switched to a bathing medium containing low $\mathrm{Ca}^{2+}(0.5 \mathrm{~mm}$ vs $2.25 \mathrm{mM})$, high $\mathrm{Mg}^{2+}(2 \mathrm{mM}$ vs $1 \mathrm{mM})$, and picrotoxin $(10 \mu \mathrm{M}) 30 \mathrm{~min}$ prior to the recording of the spontaneous burst shown in the top trace. Restoration of normal $\mathrm{Ca}^{2+}$ and $\mathrm{Mg}^{2+}(2.25$ and $1 \mathrm{~mm}$,respectively) by the addition of an equal volume of medium containing $4 \mathrm{mM} \mathrm{CaCl}$ and $0 \mathrm{MgSO}_{4}$ resulted in a rapid increase in the frequency and intensity of synaptic bursts, which frequently resulted paroxysmal-like discharges. After 30 min of restored $\mathrm{Ca}^{2+}$, rhythmic spike trains without sustained depolarizations were observed (activity usually found under the conditions used in Fig. 1). No changes in membrane potential were observed if extracellular $\mathrm{Ca}^{2+}$ was increased in the presence of TTX. $B$, Modulation of synaptic $\mathrm{Ca}^{2+}$ transients. Record of fluo-3 $\mathrm{Ca}^{2+}$ induced fluorescence from a cortical neuron in low- $\mathrm{Ca}^{2+}$ medium $0.5 \mathrm{~mm} \mathrm{CaCl}$, culture extracts were probed with anti-phosphotyrosine antibodies. Tyrosine phosphorylation of a $42 \mathrm{kDa}$ protein that comigrates with $\mathrm{p} 42 \mathrm{MAPK}$ increased in synaptically active cultures (Fig. $3 A$ ), consistent with the measurements of kinase activity. Although tyrosine phosphorylation of $\mathrm{p} 42$ MAPK was increased in synaptically active cultures, we did not observe a reproducible change in tyrosine phosphorylation of p44 MAPK (Cobb et al., $1991 \mathrm{a}, \mathrm{b})$ using the synaptic activation paradigm.

To examine the phosphorylation status of CaMK, we metabolically labeled cultures with ${ }^{32} \mathrm{P}_{\mathrm{i}}$ and immunoprecipitated this kinase using monoclonal antibodies to both $\alpha$ - and $\beta$-subunits (Fig. $3 B$ ). Inspection of the resulting SDS-PAGE autoradiogram indicated the presence of prominent labeled bands corresponding to the $\alpha-(\sim 50 \mathrm{kDa})$ and $\beta-(\sim 60 \mathrm{kDa})$ subunits. Synaptic activity or treatment of inactive cultures with the agonist kainate, which like NMDA also elicits autonomous CaMK activity (Table 1 ), produced small $(<30 \%)$ increases in total radioactivity, associated mostly with the $\beta$-subunit. Because CaMK undergoes phosphorylation at multiple sites (Gorelick et al., 1988; Schworer et al., 1988; Fukunaga et al., 1989), we excised the bands and used CNBr cleavage to isolate a peptide that contained the Thr 286 regulatory site (Fukunaga et al., 1989). This peptide was resolved using a $15 \%$ urea gel and found to undergo robust regulation in synaptically activate cultures, or synaptically inactive cultures stimulated with kainate (Fig. 3C). Excision and quantification of this band (from $\alpha$-subunit) by liquid scintillation counting indicated increases in radioactivity of up to $180 \%$ with synaptic activity, while radioactivity associated with the prominent band of $6 \mathrm{kDa}$ size increased by less than $40 \%$ with stimulation.

Although TTX and antagonists of NMDA receptors decreased CaMK activity, these treatments did not completely abolish autophosphorylation or autonomous kinase activity (Table 1; $\sim 5 \%$ autonomous activity). To investigate whether this residual activity was also regulated by $\mathrm{Ca}^{2+}$, we exposed synaptically blocked cultures to medium with no added $\mathrm{Ca}^{2+}$. Under these conditions, $\mathrm{Ca}^{2+}$-independent $\mathrm{CaMK}$ activity dropped to background levels (Table 1) and autophosphorylation of the peptide containing the Thr 286 regulatory site was undetectable (Fig. $3 D$ ). In contrast, TTX- and MK-801-insensitive MAPK activity was not reduced in the absence of added extracellular $\mathrm{Ca}^{2+}$

\section{Time course of kinase activation and decay}

In the presence of the GABA antagonist picrotoxin (Andrews and Johnston, 1979), virtually all cortical neurons within a culture exhibit highly synchronous spontaneous synaptic activity that can be monitored using intracellular $\mathrm{Ca}^{2+}$ probes or wholecell recordings (Murphy et al., 1992b). We exploited this synchronous activity to determine the time courses of CaMK and MAPK activation after initiation of synaptic activity. Since cultures show prominent spontaneous firing and associated kinase activity, we needed a method to suppress endogenous electrical activity reversibly. Previous observations indicated that by lowering extracellular $\mathrm{Ca}^{2+}$ to $0.5 \mathrm{~mm}$, and raising $\mathrm{Mg}^{2+}$ to $2 \mathrm{~mm}$, the amplitude and duration of spontaneous intracellular $\mathrm{Ca}^{2+}$

\footnotetext{
$2 \mathrm{mM} \mathrm{MgSO}_{4}$ ). When $\mathrm{Ca}^{2+}$ concentration is restored as in $A$ (arrow with $2.25 \mathrm{mM} \mathrm{CaCl}_{2}$ ), enhanced intraccllular $\mathrm{Ca}^{3+}$ transients result that can be suppressed within $10 \mathrm{sec}$ by the addition of medium containing TTX ( $1 \mu \mathrm{M}$ final) and the glutamate antagonist kynurenic acid ( $500 \mu \mathrm{M}$ final). No changes in resting intracellular $\mathrm{Ca}^{2+}$ levels were observed if the medium changes were performed in the presence of TTX $(1 \mu \mathrm{M})$.
} 
A

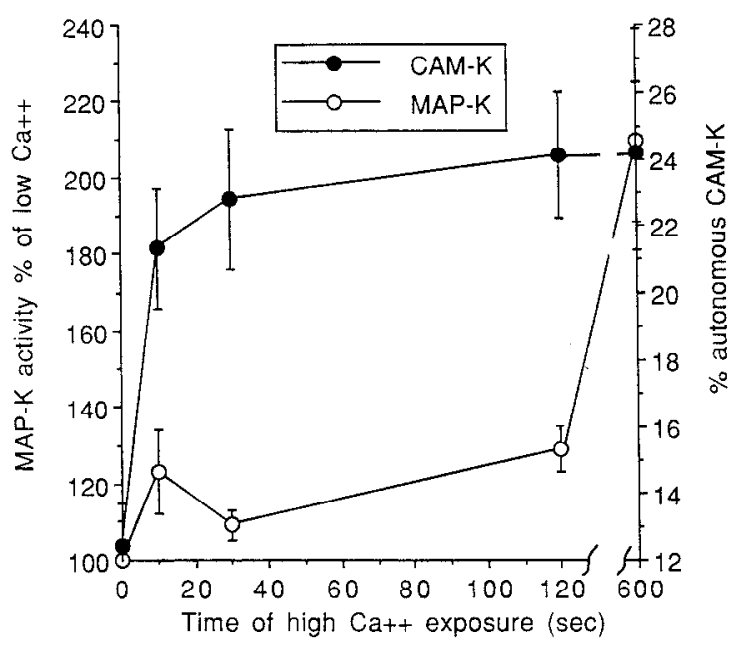

B

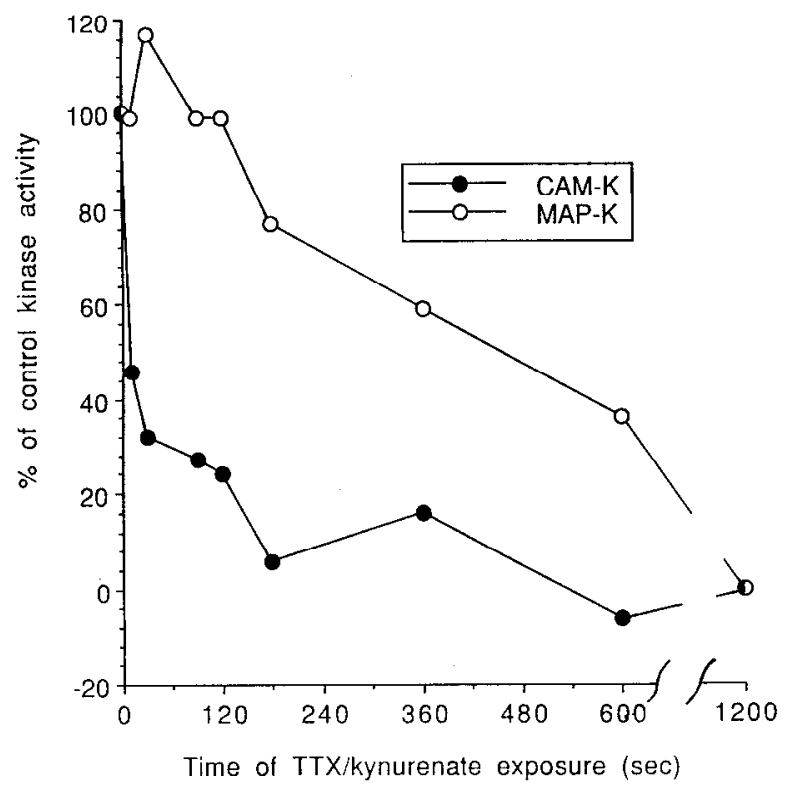

C

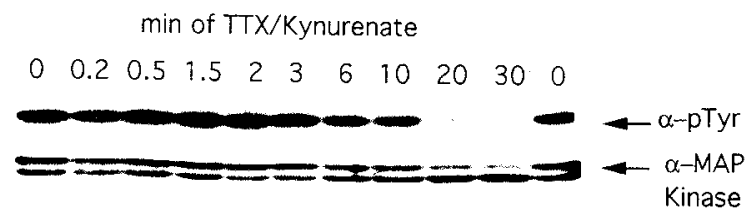

Figure 5. Kinetics of CAMK and MAPK activation and decay during synaptic transmission. $A$, Time course of kinase activation. The amplitude and duration of spontaneous bursts were suppressed for $30 \mathrm{~min}$ by lowering the extracellular $\mathrm{CaCl}_{2}$ to $0.5 \mathrm{~mm}$ as described for Figure $4 A$. Extracellular $\mathrm{CaCl}_{2}$ was then restored to $2.25 \mathrm{~mm}$ for the indicated amount of time (at room temperature) before adding stop buffer. MAPK and $\mathrm{CaMK}$ activities were measured from the same cell extracts, as described in Figure 1 and Materials and Methods. Restoration of $\mathrm{Ca}^{2+}$ levels for up to $10 \mathrm{~min}$ in the presence of TTX did not lead to increased activity for either kinase (suggesting that activation is associated with transients were suppressed, without affecting resting intracellular $\mathrm{Ca}^{2+}$ levels (Murphy et al., 1992a,b,; Fig. 4A,B). By adding an equal volume of medium containing $4 \mathrm{mM} \mathrm{Ca}^{2+}$ and $0 \mathrm{Mg}^{2+}$, normal extracellular $\mathrm{Ca}^{2+}$ and $\mathrm{Mg}^{2+}$ levels (2.25 and $1 \mathrm{~mm}$, respectively) can be rapidly restored with a concomitant TTXsensitive increase in intracellular $\mathrm{Ca}^{2+}$ transient size and spontaneous electrical activity (Murphy et al., 1992a; Fig. 4A,B). In initial studies, we observed that in cultures treated with medium containing $0.5 \mathrm{~mm} \mathrm{CaCl}_{2}$ and $2 \mathrm{~mm} \mathrm{MgSO}_{4} \mathrm{HBSS}$ for $30 \mathrm{~min}$, MAPK and CaMK activities were reduced to levels found in TTX-treated cultures maintained in regular medium $(2.25 \mathrm{~mm}$ $\mathrm{Ca}^{2+} / 1 \mathrm{mM} \mathrm{Mg}^{2+}$ ). To determine the kinetics of kinase activation, we restored $\mathrm{Ca}^{2+}$ and $\mathrm{Mg}^{2+}$ to normal levels for different amounts of time prior to harvesting the cultures. Activation of CaMK to $90 \%$ of its maximal $\mathrm{Ca}^{2+}$-independent (autonomous) activity occurred after only $10 \mathrm{sec}$ of $\mathrm{Ca}^{2+}$ restoration, while MAPK exhibited much slower kinetics and was only activated to $30 \%$ of maximal after $2 \mathrm{~min}$ (Fig. $5 \mathrm{~A}$ ). In control experiments, we confirmed that addition of low- $\mathrm{Ca}^{2+}$ medium or the addition of high- $\mathrm{Ca}^{2+}$ medium in the presence of TTX did not significantly increase activity of either kinase (Fig. 5A). Thus, the increases in kinase activity observed by changing from low to normal calcium concentration appear to be due to restoration of neuronal activity and not a consequence of the solution changes.

To study the decay of kinase activities following cessation of synaptic activity, we rapidly added an equal volume of medium that contained $2 \mu \mathrm{M}$ TTX and $1 \mathrm{~mm}$ of the broad-spectrum glutamate receptor antagonist kynurenate to cultures that had been synaptically active, in the presence of picrotoxin, for at least $30 \mathrm{~min}$ (Fig. 5B). To assure rapid and complete block of synaptic activity, both TTX and kynurenate were used. Simultaneous, fluo-3 $\mathrm{Ca}^{2+}$-induced fluorescence measurements indicated that within $10 \mathrm{sec}$ of this treatment, synaptic $\mathrm{Ca}^{2+}$ tran-

augmented synaptic activity), when compared to low- $\mathrm{Ca}^{2+}$ controls (low$\mathrm{Ca}^{2+} 12.4 \pm 1.3 \%$ CaMK autonomy vs $13.1 \pm 1.2 \%$ autonomy in low$\mathrm{Ca}^{2+}$ cultures with $\mathrm{Ca}^{2+}$ restored in the presence of $1 \mu \mathrm{M}$ TTX; $n=6$ ). MAPK activity was not significantly altered in cultures with restored $\mathrm{Ca}^{2+}$ in the presence of TTX (107 $\pm 10 \%$ of low-Ca ${ }^{2+}$ controls). The time points shown are from four to six separate experiments using duplicate cultures. $B$, Time course of kinase inactivation following suppression of synaptic activity. Cortical cultures were incubated in picrotoxin $(10 \mu \mathrm{M})$ containing HBSS (with normal $\mathrm{Ca}^{2+}$ and $\mathrm{Mg}^{2+}$ ) for at least $30 \mathrm{~min}$ at room temperature before an equal volume of medium containing TTX $(2 \mu \mathrm{M})$ and kynurenate $(1 \mathrm{mM})$ was added for the indicated time prior to harvesting cell extracts. An equal volume of HBSS containing picrotoxin, but without TTX or kynurenate, was added to controls without affecting kinase activity. To aid comparison of the two time courses, CaMK autonomy and MAPK activity are expressed as a percentage of stimulated activity, with $100 \%$ corresponding to untreated cultures, and zero corresponding to $20 \mathrm{~min}$ of TTX and kynurenate treatment. The results shown were derived from the means of two separate experiments performed in duplicate. $C$, Loss of MAPK tyrosine phosphorylation parallels kinase activity. Approximately $40 \mu \mathrm{g}$ of soluble protein derived from a cell extract used in $B$ was resolved using SDS-PAGE, transferred to nitrocellulose, and probed sequentially with antibodies to phosphotyrosine and MAPK. When the blot was reprobed with antibodies to MAPK (C-terminal polyclonal antibody used), two bands were apparent that were distinct from other MAPK family members (p44). Phosphorylation of MAPK slows its migration in SDS-PAGE. Thus, as expected, the phosphotyrosine band comigrates with the upper band of the MAPK doublet. In the samples from the 20 and $30 \mathrm{~min}$ time points, a loss of the upper MAPK band with a complementary increase in the lower band is apparent, consistent with the loss of phosphotyrosine reactivity. 


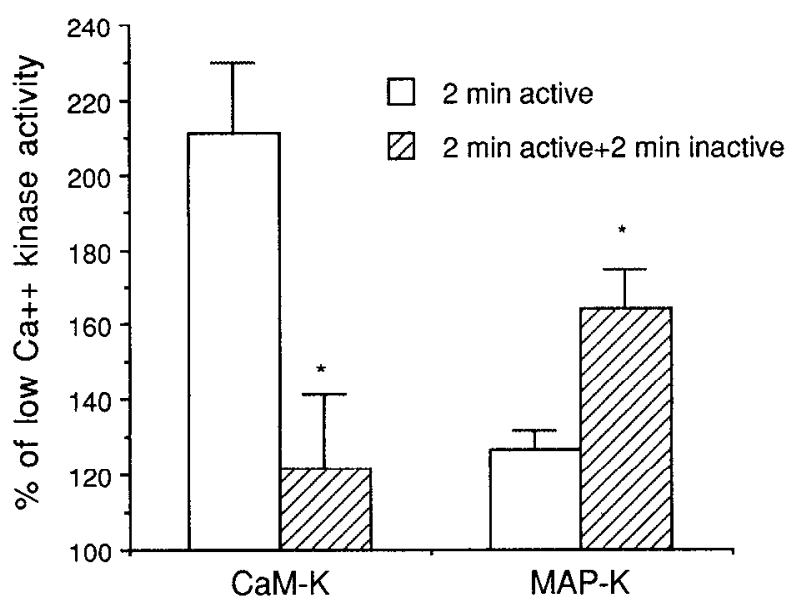

Figure 6. Delayed onset of MAPK kinase activity following short periods of synaptic activity. Neurons were incubated with low-Ca ${ }^{2+}$, high$\mathrm{Mg}^{2+}$ medium $(0.5,2 \mathrm{~mm}$ respectively) as described in Figures 4 and 5 for approximately $30 \mathrm{~min}$ before restoring normal $\mathrm{Ca}^{2+}$ and $\mathrm{Mg}^{2+}$ levels for $2 \mathrm{~min}$ followed by addition of stop buffer, or a $2 \mathrm{~min}$ period of electrical silence (TTX and kynurenic acid added as in Fig. $5 B$, and confirmed by simultaneous fluo-3 measurements). CaMK and MAPK activities were measured from the same extracts. Results are means \pm SEM of at least four separate experiments. ${ }^{*}, P<0.05$, unpaired $t$ test comparing kinase activity following the indicated treatments for each kinase.

sients were completely blocked (Fig. $4 B$ ). Measurement of kinase activities after this maneuver indicated that MAPK and CaMK display vastly different decay kinetics. Following suppression of synaptic activity, CaMK activity decayed by $50 \%$ within $10-30$ sec, while MAPK decayed by only $50 \%$ within $6-10$ min (Fig. $5 B$ ). Phosphotyrosine immunoblots indicated a loss of tyrosine phosphorylation of MAPK that paralleled its loss of activity (Fig. $5 C$ ). Reprobing of this blot with a MAPK antiserum indicated comparable loading of MAPK in each lane. Immunoblots with the MAPK antibody also indicated a shift in p42 MAPK mobility (Posada and Cooper, 1992) in inactive cultures that would be consistent with dephosphorylation (Fig. $5 C$ ).

Relatively long periods of synaptic activity were required to stimulate MAPK. We wondered whether this reflected a requirement for prolonged stimulation to induce activation, or alternatively, a lag in MAPK activation that could be triggered by a brief exposure to synaptic stimulation. To distinguish between these possibilities, we investigated whether shorter periods of electrical activity followed by an inactive period would also stimulate MAPK. To perform this experiment, two sets of cultures were treated with low-Ca ${ }^{3+}$ medium $\left(0.5 \mathrm{mM} \mathrm{Ca}^{3+}, 2\right.$ $\mathrm{mM} \mathrm{Mg}^{2+}$ ) for about $30 \mathrm{~min} ; \mathrm{Ca}^{2+}$ and $\mathrm{Mg}^{2+}$ levels were then restored for $2 \mathrm{~min}$ (Fig. 6). At this time, extracts were harvested from one set of cultures, and synaptic activity was blocked in the other by adding TTX/kynurenate for an additional $2 \mathrm{~min}$ before harvesting (Fig. 6). In cultures that were harvested immediately after 2 min of synaptic stimulation, MAPK activity was elevated by $30 \%$ over low- $\mathrm{Ca}^{2+}$ controls, while CaMK activity was maximal. Interestingly, in cultures exposed to $2 \mathrm{~min}$ of activity followed by 2 min of electrical silence, MAPK activity was increased further, to $60 \%$ above the low- $\mathrm{Ca}^{2+}$ controls. In contrast, stimulated CaMK activity in these extracts was decreased by $80 \%$. The ability of MAPK activity to increase even after removing the stimulus suggests that the slow onset of activation may reflect the time required for signals to propagate through the kinase cascade mediating MAPK activation.

\section{Discussion}

Information in neuronal signaling is often conveyed through the temporal pattern of synaptic discharges. For example, different stimulation patterns can lead to long-term potentiation (LTP), short-term potentiation, or even long-term depression of a particular input (Abraham and Goddard, 1983; Levy and Steward, 1983; Malenka, 1991; Christie and Abraham, 1992; Dudek and Bear, 1992; Mulkey and Malenka, 1992). In addition, patterned stimulation has been implicated in regulation of growth cone morphology (Fields et al., 1990). However, little is known about the temporal characteristics of the signaling pathways that underlie this remarkable versatility in neuronal responses. To address this question, we have, in this study, investigated the synaptic regulation of two protein kinases, CaMK and MAPK, thought to be involved in postsynaptic signal transduction. These protein kinases are well suited for this comparison since they have markedly different mechanisms of activation that may allow them to interact with different aspects of synaptic activity. We have found that these kinases differ markedly in their activation and decay kinetics, and sensitivity to NMDA receptor antagonists.

Previous studies indicate that receptor agonists can activate MAPK (Stratton et al., 1989; Bading and Greenberg, 1991) and CaMK (Fukunaga et al., 1992). However, regulation of these kinases by synaptic stimuli has not been reported. During synaptic stimulation only a subset of synaptic receptors appear to be activated intermittently by released transmitter. By contrast, during agonist addition both synaptic and extrasynaptic receptors would be activated for relatively long periods of time. Our results provide evidence that the activity of these kinases can be regulated by the rapid and spatially discrete action of synaptic transmission.

Analysis of CaMK and MAPK activation by synaptic stimulation indicated markedly different kinetics. CaMK activity reached $90 \%$ of maximal after only $10 \mathrm{sec}$ of stimulation, the shortest time point examined. Given some lag time for mixing of solutions, the CaMK data agree well with results obtained in vitro with purified CaMK or calmodulin-activated kinases such as myosin light chain kinase (Taylor et al., 1989). Furthermore, recent studies in hippocampal neurons demonstrate that a $2 \mathrm{sec}$ rise in intracellular $\mathrm{Ca}^{2+}$ is sufficient to elicit LTP (Malenka et al., 1992). As LTP is dependent on CaMK activation (Malenka et al., 1989; Malinow et al., 1989), these findings provide additional evidence for rapid activation of $\mathrm{CaMK}$.

MAPK exhibited much slower activation kinetics than CaMK, with only $30 \%$ of maximal activation achieved after 2 min of stimulation. Although the steps leading from synaptic stimulation to MAPK activation have not been identified, several lines of evidence point to a role for the phosphoinositide (PI)PKC pathway. Previous studies suggest that MAPK can be activated by phorbol esters or transmitter receptor agonists that promote PI turnover (Stratton et al., 1989). In a recent study, we have found that synaptic activity in primary cortical cultures is associated with a high degree of PI turnover. Like the activation of MAPK by synaptic activity reported here, PI turnover associated with synaptic activity was not dependent on NMDA receptor activation (Murphy et al., 1992a). Thus, synaptic activation of the PI system, possibly via activation of metabotropic glutamate receptors (Miller, 1991), may lead to activation of MAPK. Consistent with this proposal, trans-ACPD (Palmer et al., 1989), an agonist at metabotropic glutamate receptors, 
activates MAPK in synaptically inactive (TTX-trcatcd) cortical cultures (Fiore et al., 1993b). Although stimulation of PKC can induce MAPK activation, it probably acts indirectly since an activator kinase, that phosphorylates MAPK on both tyrosine and threonine in vitro is activated by phorbol esters in intact cells (Rossomondo et al., 1992). Thus, the slow activation of MAPK by synaptic activity may reflect the multiple intermediate steps involved. Consistent with this proposal, shorter periods of activity followed by an inactive period were also effective at inducing MAPK (Fig. 6). Alternatively, the delayed response may reflect indirect activation of MAP kinase by release of neurotrophins or other factors.

To help define the postulated role of autonomous kinases in storage of information, we examined the decay of kinase activity after cessation of synaptic activity. CaMK exhibited a more rapid decay of stimulated activity than MAPK, with the halflives being $\sim 30$ and $600 \mathrm{sec}$, respectively. The rapid decay of stimulated CaMK activity suggests that this kinase may not be a long-term storage device. Alternatively, CaMK may be a rapid, transient effector of synaptic function, and possibly serve as a trigger of other longer-lived effects. The relatively slow decay in MAPK activity may reflect a slower rate of its dephosphorylation when compared to CaMK. However, it is important to consider that MAPK activation appears to go on even' after synaptic activity has stopped. Thus, the persistent activity may also reflect the lag required for ongoing phosphorylation of MAPK by activator kinases to subside. The ability of MAPK activation to proceed in the absence of synaptic activity suggests that this kinase is well suited to integrate information from infrequent, but repetitive bursts of synaptic activity. In contrast, the rapid activation-inactivation kinetics of CaMK would allow it to follow synaptic stimuli of higher frequency. Additional levels of CaMK regulation may also be achieved through the trapping of bound calmodulin by autophosphorylated $\mathrm{CaMK}$, which increases its probability of activation (Meyer et al., 1992).

Autonomous activity of both MAPK and CaMK is dependent on phosphorylation of these proteins. Although we have monitored the phosphotyrosine status of MAPK, we have not directly assayed Thr phosphorylation. Since active MAPK requires both Tyr and Thr phosphorylation (Anderson et al., 1990) we assume that Thr phosphorylation is present. Studies directly examining phosphorylation of the Thr site are needed to determine whether it is regulated in parallel with the tyrosine phosphorylation or not. Differential regulation of these two sites could provide a means of altering the temporal profile of MAPK activation or inactivation.

Immunoprecipitation of labeled CaMK from ${ }^{32} \mathrm{P}$-labeled cultures and subsequent $\mathrm{CNBr}$ cleavage suggested that $\mathrm{CaMK}$ autonomous activity correlates well with the phosphorylation of a peptide containing Thr 286 . This site appeared to be affected selectively by synaptic activity or depolarization with kainate. Consistent with previous reports (Gorelick et al., 1988; Fukunaga et al., 1989), at least three other sites were also phosphorylated. However, phosphorylation of these other sites was much less sensitive to synaptic stimulation or even exposure to medium without added $\mathrm{Ca}^{2+}$.

In the complete absence of synaptic activity (TTX and MK801 added; cells at resting membrane potential, and low intracellular $\mathrm{Ca}^{2+}$ ) some autonomous CaMK activity $(\sim 5 \%)$ remained. Several lines of evidence indicate that this is due to residual CaMK activity, rather than another kinase. This activity was abolished when extracellular $\mathrm{Ca}^{2+}$ was removed, it was reduced by peptide CaMK inhibitors (see Materials and Methods), and it correlated with Thr 286 phosphorylation. A previous study by Molloy and Kennedy (1991) reported the presence of autonomous CaMK activity with similar characteristics in cultured hippocampal slices; however, in that system this activity accounted for $25 \%$ of the autonomous CaMK activity. Perhaps the cortical culture preparation used in this study contains higher levels of protein phosphatase activity that reduce the basal autonomous CaMK activity to $\sim 5 \%$.

The observation that NMDA receptor antagonists were very effective at suppressing synaptic activation of CaMK implied that calcium transients induced by synaptic activity are largely dependent on NMDA receptor stimulation. To test this prediction, we undertook studies aimed at measuring calcium transients in dendrites, as CaMK is expressed at high levels in neuronal dendrites and thought to be concentrated in the vicinity of postsynaptic elements (Kennedy et al., 1990). Calcium imaging in fine dendritic processes $(\sim 1 \mu \mathrm{m}$ in diameter) suggested that NMDA receptor blockade reduces synaptic $\mathrm{Ca}^{2+}$ transients by more than $85 \%$ (Fig. 2), consistent with previous studies of hippocampal neurons (Regehr and Tank, 1990; Muller and Connor, 1991). Assays of CaMK activity also indicated that NMDA antagonists block CaMK autonomy more effectively than TTX. This finding suggests that action potential-independent release of glutamate may be sufficient to stimulate NMDA receptors. Conceivably, this could occur locally and transiently at sites of spontaneous glutamate release or tonically by ambient glutamate (Sah et al., 1989; Blanton et al., 1990). The former possibility, that miniature synaptic currents contribute to NMDA receptor activation, is supported by recent studies investigating calcium transients induced by these events (Murphy et al., 1993). In these experiments, imaging of intracellular calcium was performed in dendrites in the presence of TTX to detect spontaneous synaptic events, and in the absence of $\mathrm{Mg}^{2+}$, to augment NMDA receptor activation. Under these conditions, calcium transients that were restricted to small dendritic segments $(<15$ $\mu \mathrm{m})$ were detected that were completely blocked by $\mathrm{D}, \mathrm{L}-\mathrm{APV}$.

In summary, our results indicate that CaMK and MAPK display distinct temporal profiles of activation and inactivation. Thus, if present in the same neurons, they could function to discriminate between different patterns of afferent activity. We propose that the sluggish response of MAPK may be particularly important in allowing neurons to respond to infrequent, repetitive stimuli. The availability of antibodies capable of selectively detecting the phosphorylated forms of these kinase would be helpful in determining whether the activities assayed in vitro are colocalized in situ.

\section{References}

Abraham WC, Goddard GV (1983) Asymmetric relations between homosynaptic long-term potentiation and heterosynaptic long-term depression. Nature 305:717-719.

Ahn NG, Robbins DJ, Haycock JW, Seger R, Cobb MH, Krebs EG (1992) Identification of an activator of the microtubule-associated protein 2 kinases ERK1 and ERK2 in PC1 2 cells stimulated with nerve growth factor or bradykinin. J Neurochem 59:147-156.

Anderson NG, Maller JL, Tonks NK, Sturgill TW (1990) Requirement for integration of signals from two distinct phosphorylation pathways for activation of MAP kinase. Nature 343:651-653.

Andrews PR, Johnston GAR (1979) GABA agonists and antagonists. Biochem Pharmacol 28:2697-2702.

Bading H, Greenberg ME (1991) Stimulation of protein tyrosine phosphorylation by NMDA receptor activation. Science 253:912-914.

Baraban JM, Fiore RS, Sanghera JS, Paddon HB, Pelech SL (1993) Identification of $\mathrm{p} 42 \mathrm{MAP}$ kinase as a tyrosine kinase substrate ac- 
tivated by electroconvulsive treatment in hippocampus. J Neurochem 60:330-336.

Bashir ZI, Collingridge GL (1992) Synaptic plasticity: long-term potentiation in the hippocampus. Curr Biol 2:328-335.

Blanton MG, Lo Turco JJ, Kriegstein AR (1990) Endogenous neurotransmitter activates $N$-methyl-D-aspartate receptors on differentiating neurons in embryonic cortex. Proc Natl Acad Sci USA 87: 8027-8030.

Blatter LA, Wier WG (1990) Intracellular diffusion, binding, and compartmentalization of the fluorescent calcium indicators indo- 1 and fura-2. Biophys J 58:1491-1499.

Blatter LA, Wier WG (1992) Agonist-induced [Ca2+]i waves and $\mathrm{Ca}(2+)$-induced $\mathrm{Ca} 2+$ release in mammalian vascular smooth muscle cells. Am J Physiol 263:H576-H586.

Christie BR, Abraham WC (1992) Priming of associative Iong-term depression in the dentate gyrus by theta frequency synaptic activity. Neuron 9:79-84.

Clark-Lewis I, Sanghera JS, Pelech SL (1991) Definition of a consensus sequence for peptide substrate recognition by $\mathrm{p} 44^{\mathrm{mpk}}$, the meiosisactivated myelin basic protein kinase. J Biol Chem 266:15180-15184.

Cobb MH, Boulton TG, Robbins DJ (1991a) Extracellular signalregulated kinases: ERKs in progress. Cell Regul 23:965-978.

Cobb MH, Robbins DJ, Boulton TG (1991b) ERKs, extracellular signal-regulated MAP-2 kinases. Curr Opin Cell Biol 3:1025-1032.

Dichter MA (1978) Rat cortical neurons in cell culture: culture methods, cell morphology, electrophysiology, and synapse formation. Brain Res 149:279-293.

Dudek SM, Bear MF (1992) Homosynaptic long-term depression in area CA1 of hippocampus and the effects of $N$-methyl-D-aspartate receptor blockade. Proc Natl Acad Sci USA 89:4363-4367.

Erickson AK, Payne DM, Martino PA, Rossomando AJ, Shabanowitz J, Weber M, Hunt DF, Sturgill TW (1990) Identification by mass spectrometry of threonine 97 in bovine myelin basic protein as a specific phosphorylation site for mitogen-activated protein kinase. J Biol Chem 265:19728-19735.

Fields RD, Neale EA, Nelson PG (1990) Effects of patterned electrical activity on neurite outgrowth from mouse sensory neurons. J Neurosci 10:2950-2964.

Fiore RS, Bayer V, Pelech SL, Posada J, Cooper JA, Baraban JM (1993a) p42 mitogen-activated protein kinase in brain: prominent localization in neuronal cell bodies and dendrites. Neuroscience 55:463-472.

Fiore RS, Murphy TH, Sanghera JS, Pelech SL, Baraban JM (1993b) Activation of $\mathrm{p} 42$ MAP kinase by glutamate receptor stimulation in rat primary cortical cultures. J Neurochem 61:1626-1633.

Fukunaga K, Rich DP, Soderling TR (1989) Generation of the $\mathrm{Ca}^{2+}$ independent form of $\mathrm{Ca}^{2+} / \mathrm{calmodulin}-d e p e n d e n t$ protein kinase II in cerebellar granule cell. J Biol Chem 264:21830-21836.

Fukunaga K, Soderling TR, Miyamoto E (1992) Activation of $\mathrm{Ca}^{++} /$ calmodulin-dependent protein kinase II and protein kinase $\mathrm{C}$ by glutamate in cultured rat hippocampal neurons. J Biol Chem 267:2252722533.

Gorelick FS, Wang JKT, Lai Y, Nairn AC, Greengard P (1988) Autophosphorylation and activation of $\mathrm{Ca}^{2+} /$ calmodulin-dependent protein kinase II in intact nerve terminals. J Biol Chem 263:1720917212 .

Grynkiewicz G, Poenie M, Tsien RY (1985) A new generation of calcium indicators with greatly improved fluorescence properties. J Biol Chem 260:3440-3450.

Hanson PI, Schulman H (1992) Neuronal $\mathrm{Ca}^{2+} /$ calmodulin-dependent protein kinases. Annu Rev Biochem 61:559-601.

Kelly PT (1992) Calmodulin-dependent protein kinase II. Mol Neurobiol 5:153-177.

Kennedy MB, Bennett MK, Erondu NE (1983) Biochemical and immunochemical evidence that the major postsynaptic density protein is a subunit of a calmodulin-dependent protein kinase. Proc Natl Acad Sci USA 80:7357-7361

Kennedy MB, Bennett MK, Bulleit RF, Erondu NE, Jennings VR, Miller SG, Molloy SS, Patton BL, Schenker LJ (1990) Structure and regulation of type II calcium/calmodulin-dependent protein kinase in central nervous system neurons. Cold Spring Harbor Symp Quant Biol 55:101-110.

Klann E, Chen SJ, Sweatt JD (1991) Persistent protein kinase activation in the maintenance phase of long term potentiation. J Biol Chem 266:24253-24256.
Laemmli UK (1970) Cleavage of structural proteins during the assembly of the head of bacteriophage T4. Nature 227:680-684.

Levy WB, Steward O (1983) Temporal contiguity requirements for long-term associative potentiation/depression in the hippocampus. Neuroscience 8:791-797

Lisman JE (1985) A mechanism for memory storage insensitive to molecular turnover: a bistable autophosphorylating kinase. Proc Natl Acad Sci USA 82:3055-3057.

MacNicol M, Jefferson AB, Schulman H (1990) $\mathrm{Ca}^{2+} /$ calmodulin kinase is activated by the phosphatidylinositol signaling pathway and becomes $\mathrm{Ca}^{2+}$-independent in PC12 cells. J Biol Chem 265:1805518058.

Malenka RC (1991) Postsynaptic factors control the duration of synaptic enhancement in area CA1 of the hippocampus. Neuron 6:5360.

Malenka RC, Kauer JA, Perkel DJ, Mauk MD, Kelly PT, Nicoll RA, Waxham MN (1989) An essential role for postsynaptic calmodulin and protein kinase activity in long-term potentiation. Nature 340 : 554-557.

Malenka RC, Lancaster B, Zucker RS (1992) Temporal limits on the rise in postsynaptic calcium required for the induction of long-term potentiation. Neuron 9:12l-128.

Malinow R, Madison DV, Tsien RW (1988) Persistent protein kinase activity underlying long-term potentiation. Nature 335:820-824.

Malinow R, Schulman H, Tsien RW (1989) Inhibition of postsynaptic PKC or CaMKII blocks induction but not expression of LTP. Science 245:862-866

Meyer T, Hanson PI, Stryer L, Schulman H (1992) Calmodulin trapping by calcium-calmodulin-dependent protein kinase. Science 256 . $1199-1202$

Miller RJ (1991) Metabotropic glutamate receptors reveal their true colors. Trends Pharmacol Sci 12:365-368.

Minta A, Kao J, Tsien RY (1989) Fluorescent indicators for cytosolic calcium based on rhodamine and fluorescein chromophores. J Biol Chem 264:8171-8178.

Molloy SS, Kennedy MB (1991) Autophosphorylation of type II Ca ${ }^{++1}$ calmodulin-dependent protcin kinase in cultures of postnatal rat hippocampal slices. Proc Natl Acad Sci USA 88:4756-4760.

Monaghan DT, Bridges RJ, Cotman CW (1989) The excitatory amino acid receptors: their classes, pharmacology, and distinct properties in the function of the central nervous system. Annu Rev Pharmacol Toxicol 29:365-402.

Mulkey RM, Malenka RC (1992) Mechanisms underlying induction of homosynaptic long-term depression in area CAl of the hippocampus. Neuron 9:967-975.

Muller W, Connor JA (1991) Dendritic spines as individual neurona compartments for synaptic $\mathrm{Ca}^{2+}$ responses. Nature 354:73-76.

Murphy TH, Baraban JM (1990) Glutamate toxicity in immature cortical neurons precedes development of glutamate receptor currents. Dev Brain Res 57:146-150.

Murphy TH, Worley PF, Baraban JM (1991a) L-type voltage sensitive calcium channels mediate synaptic activation of immediate early genes. Neuron 7:625-635.

Murphy TH, Worley PF, Nakabeppu Y, Christy B, Gastel J, Baraban JM (1991b) Synaptic regulation of immediate early gene expression in primary cultures of cortical neurons. J Neurochem 57:1862-1872.

Murphy TH, Wright DD, Baraban JM (1992a) Phosphoinositide turnover associated with synaptic transmission. J Neurochem 59:23362339.

Murphy TH, Blatter LA, Wier WG, Baraban JM (1992b) Spontaneous synchronous calcium transients in cultured cortical neurons. J Neurosci 12:4834-4845.

Murphy TH, Baraban JM, Wier WG, Blatter LA (1993) Local dendritic calcium transients induced by quantal synaptic transmission. Soc Neurosci Abstr 19:432.

Nakielny S, Cohen P, Wu J, Sturgill T (1992) MAP kinase activator from insulin-stimulated skeletal muscle is a protein threonine/tyrosine kinase. EMBO J 11:2123-2129.

Ocorr KA, Schulman H (1991) Activation of multifunctional $\mathrm{Ca}^{2+}$ calmodulin-dependent kinase in intact hippocampal slices. Neuron 6:907-914.

Palmer E, Monaghan DT, Cotman CW (1989) trans-ACPD, a selective agonist of the phosphoiniositide-coupled excitatory amino acid receptor. Eur J Pharmacol 166:585-587. 
Payne DM, Rossomando AJ, Martino P, Erikson AK, Her J-H, Shabanowitz J, Hunt DF, Weber MJ, Sturgill TW (1991) Identification of the regulatory phosphorylation sites in $\mathrm{pp} 42 /$ mitogen-activated protein kinase (MAP kinase). EMBO J 10:885-892.

Pelech SL, Sanghera JS (1992) MAP kinase charting the regulatory pathways. Science 257:1355-1356.

Posada J, Cooper JA (1992) Requirements for phosphorylation of MAP kinase during meiosis in Xenopus oocytes. Science 255:212215.

Regehr WG, Tank DW (1990) Postsynaptic NMDA receptor mediated calcium accumulation in hippocampal CA 1 pyramidal cell dendrites. Nature 345:807-810.

Rossomando A, Wu J, Weber MJ, Sturgill TW (1992) The phorbol ester-dependent activator of the mitogen-activated protein kinase p42 mapk is a kinase with speciticity for the threonine and tyrosine regulatory sites. Proc Natl Acad Sci USA 89:5221-5225.
Sah P, Hestrin S, Nicoll, RA (1989) Tonic activation of NMDA receptors by ambient glutamate enhances excitability of neurons. Science 246:815-818.

Schworer CM, Colbran RJ, Keefer JR, Soderling TR (1988) $\mathrm{Ca}^{2+}$ calmodulin-dependent protein kinase II. J Biol Chem 263:1348613489 .

Stratton KR, Worley PF, Huganir RL, Baraban JM (1989) Muscarinic agonists and phorbol esters increase tyrosine phosphorylation of a 40 kilodalton protein in hippocampal slices. Proc Natl Acad Sci USA $86: 2498-2501$.

Taylor DA, Bowman BF, Stull JT (1989) Cytoplasmic $\mathrm{Ca}^{2+}$ is a primary determinant for myosin phosphorylation in smooth muscle cells. J Biol Chem 264:6207-6213.

Wong EHF, Kemp JA, Priestly T, Knight AR, Woodruff GN, Iversen LL (1986) The anticonvulsant MK-801 is a potent $N$-methyl-Daspartate antagonist. Proc Natl Acad Sci USA 83:7104-7108. 